\title{
Auto-Ignition of a Hexadecane Droplet Mixed with Different Octane Number Fuels at Elevated Pressures To Investigate the Pre-Ignition ${ }_{3}$ Behavior
}

\author{
${ }_{4}$ Hatsari Mitsudharmadi, ${ }^{*},{ }^{\dagger} \odot$ Sumit Maharjan, ${ }^{\dagger}$ Ayman M. Elbaz, ${ }^{\dagger}$ Yasser A. Qahtani, ${ }^{\ddagger}$ \\ $s$ and William L. Roberts \\ $6{ }^{\dagger}$ Clean Combustion Research Center, King Abdullah University of Science and Technology, Thuwal 23955-6900, Kingdom of Saudi \\ 7 Arabia \\ 8 ARAMCO, Dhahran 31311, Saudi Arabia
}

\begin{abstract}
9 ABSTRACT: Pre-ignition is an abnormal combustion event that may occur in boosted direct injection gasoline engines, where 10 one or more auto-ignition events are observed before spark ignition. Due to the direct injection of fuel into the cylinder, some 11 liquid fuel may splash off the walls, pulling lubricating oil with it. The auto-ignition of liquid fuel/lubricant droplets is 12 considered as one of the possible sources of pre-ignition. To assess this stochastic phenomenon in a controlled way, the auto13 ignition of a single droplet of a hexadecane-fuel mixture was investigated, with hexadecane serving as a surrogate for the 14 lubricating oil. This experiment included suspending a single hexadecane-fuel mixture droplet on a thermocouple bead in 15 preheated air, at a temperature of $300 \pm 4{ }^{\circ} \mathrm{C}$, in a constant volume chamber over a wide range of pressures (4-30 bar). Four different fuels with a range of research octane number (RON) between 70 and 120 were mixed with hexadecane at a volume percentage of $75 \%$ hexadecane to $25 \%$ fuel to investigate the time to ignition of the droplet, designated as TI. The TI was measured by recording the droplet temperature history simultaneously with high-speed droplet imaging. The droplet ignition is triggered by the auto-ignition of the combustible mixture formed by the hexadecane-fuel mixture's vapor that mixes with the hot ambient air around the droplet. An empirical model was proposed to predict the TI in terms of pressure and the mixture's RON. At constant pressure, the rate of evaporation of the mixture's droplet increases with increasing RON. The time to ignition is seen to increase exponentially as the fuel's RON used in the mixture increases. On the other hand, for a given fuel RON, the time to ignition decreases with increasing ambient pressure. The empirical model shows that at pressures above 20 bar, the dilution of hexadecane by the different fuels has no significant effect on delaying the auto-ignition of the droplet.
\end{abstract}

\section{INTRODUCTION}

26 Automotive manufacturers are continually endeavoring to 27 improve the performance and efficiency of internal combustion 28 engines to reduce fuel consumption and emissions. Downsized 29 boosted gasoline direct injection (GDI) engines are a 30 promising technology to achieve these goals. Downsizing 31 engines allow for extracting the same power from smaller 32 engines, which reduces the amount of the air-fuel mixture that 33 goes into a naturally aspirated engine. However, such 34 technology remains constrained by several abnormal combus35 tion phenomena, such as knock and pre-ignition. A new 36 destructive combustion mode, known as low-speed pre37 ignition (LSPI), is occasionally observed in these highly 38 boosted GDI engines. ${ }^{1,2}$ The LSPI combustion mode is 39 characterized as a stochastic phenomenon that results in the 40 transformation of a normal propagating flame to a severe 41 knocking event ${ }^{1,2}$ and begins before the firing of the spark plug. 42 This pre-ignition event may be initiated by an ignition source 43 such as hot spots in the chamber and carbon particle deposits 44 from the previous cycle.

45 The potential causes of LSPI, such as auto-ignition in the 46 gaseous phase and the ignition of the fuel-air mixture due to 47 either liquid droplets or solid particles, were described by 48 Zaccardi and Escudié. ${ }^{3}$ The early occurrence of LSPI before 49 the spark timing may lead to flame propagation that results in too rapid pressure rises due to the advanced combustion 50 phasing. This may cause violent end gas knock or even super- 51 knock for events that transition to developing detonation. ${ }^{4} 52$ However, not all LSPI cycles exhibit super-knock. ${ }^{5}$

Toyota Motors and JX Nippon Oil and Energy Corporation 54 investigated the effect of fuel compounds on pre-ignition under 55 high-temperature and high-pressure conditions. ${ }^{6}$ They inves- 56 tigated the effects of pre-ignition temperature, which, under 57 their conditions, was lower compared to a naturally aspirated 58 engine. They reported that pre-ignition temperature showed a 59 better correlation with the motor octane number (MON) and 60 auto-ignition temperature compared to the research octane 61 number $(\mathrm{RON})$. However, the complete mechanism of the 62 fuel reaction was not determined in their study. ${ }^{6}$

Amann et al. ${ }^{1}$ demonstrated that fuel chemical composition 64 had a strong impact on the occurrence and intensity of LSPI. 65 Their study showed an increase in LSPI occurrence with fuel 66 blends with high levels of aromatics. On the contrary, 67 oxygenated fuels and low aromatic blends reduced the 68 frequency of LSPI occurrence. Furthermore, they observed 69 different knock and auto-ignition characteristics of the test 70

Received: July 31, 2019

Revised: November 22, 2019

Published: November 24, 2019 


\section{Table 1. List of the Previous Works Related to the Droplet Ignition in Conjunction with the Pre-Ignition Phenomenon}

\begin{tabular}{|c|c|c|}
\hline authors & experimental procedure & observation \\
\hline Jatana et al. ${ }^{14}$ & $\begin{array}{l}\text { Experiments were conducted in a Ford Ecoboost engine. Cyclopentanone, 2-methyl-1- } \\
\text { butanol, and ethylbenzene were mixed at } 25 \% \text { concentration with gasoline. }\end{array}$ & $\begin{array}{l}\text { All mixtures approximately doubled the pre-ignition occurrence } \\
\text { compared to baseline gasoline fuel. }\end{array}$ \\
\hline Fei et al. ${ }^{16}$ & $\begin{array}{l}\text { Experiments were conducted in a rapid compression machine (RCM). Lubricant oil } \\
\text { droplet ignition in the fuel-air mixture was investigated at elevated temperatures and } \\
\text { pressures. }\end{array}$ & $\begin{array}{l}\text { For their experimental conditions, the ignition delay time of the fuel- } \\
\text { air mixture was not affected by lubricant oil droplets. }\end{array}$ \\
\hline $\begin{array}{l}\text { Zahdeh et } \\
\text { al. }^{2}\end{array}$ & $\begin{array}{l}\text { Experiments were conducted in a four-cylinder engine. Pre-ignition event was } \\
\text { investigated for single and double injection for a different oil. }\end{array}$ & $\begin{array}{l}\text { Ignition of the diluted fuel-oil mixture was identified as a reason } \\
\text { behind the auto-ignition of the fuel. }\end{array}$ \\
\hline Amann et al. ${ }^{1}$ & $\begin{array}{l}\text { Experiments were conducted in a boosted gasoline direct injection engine. A standard } \\
\text { gasoline fuel with an octane rating of } 87 \text { and } 5 W 20 \text { lubricant oil was used. }\end{array}$ & $\begin{array}{l}\text { Among other reasons, the chemical and physical properties of the } \\
\text { fuel and lubricant could cause pre-ignition. }\end{array}$ \\
\hline$\underset{\text { al. }^{13}}{\text { Dahnz et }}$ & $\begin{array}{l}\text { Experiments were conducted in a turbocharged, gasoline direct-injection 4-cylinder } \\
\text { engine. }\end{array}$ & $\begin{array}{l}\text { Lubricant oil droplets released from the piston top land into the } \\
\text { combustion chamber could cause pre-ignition. }\end{array}$ \\
\hline $\begin{array}{l}\text { Ohtomo et } \\
\text { al. }^{10}\end{array}$ & $\begin{array}{l}\text { Experiments were conducted in RCM in a fuel-air mixture environment where a single } \\
\text { oil droplet was injected. }\end{array}$ & $\begin{array}{l}\text { The initial droplet temperature had to be higher, in their case, more } \\
\text { than } 250{ }^{\circ} \mathrm{C} \text { for the oil vapor to ignite before the fuel-air mixture. }\end{array}$ \\
\hline $\begin{array}{l}\text { Kuboyama et } \\
\text { al. }^{15}\end{array}$ & $\begin{array}{l}\text { Experiments were conducted in a four-cylinder engine to investigate the effect of engine } \\
\text { operating parameters. Imaging techniques were implemented in the study. }\end{array}$ & $\begin{array}{l}\text { Several sources were observed to be causing pre-ignition in an } \\
\text { engine, such as glowing particles, deposit fragments, and lubricant } \\
\text { oil droplets. }\end{array}$ \\
\hline
\end{tabular}

71 fuels in the DI-SI engine even with similar RON and MON 72 ratings. Based on their findings and previous studies, they 73 suggested the lubricant or fuel-based hydrocarbon deposits on 74 the piston crevices as the leading cause of LSPI. In a study of 75 the effect of market variations in gasoline composition on 76 aspects of stochastic pre-ignition (SPI), Mansfield et al. ${ }^{7}$ found 77 a strong indication that the main effect of aromatic plus olefin 78 on primary SPI frequency is to enhance deposit dynamics. 79 These deposits increase the possible sites where the number of 80 ignitions can occur and hence increases the frequency of the 81 SPI event.

82 Kalghatgi and Bradley ${ }^{8}$ concluded that the pre-ignition in 83 turbocharged engines is characterized by (i) higher pressures 84 and temperatures briefly attributing in the rise to gas-phase 85 pre-ignition; (ii) auto-ignition at even higher pressures and 86 temperatures, which might result in severe knock; (iii) injector 87 sprays striking surrounding surfaces and stripping lubricating 88 oil from them; (iv) lubricant mixing with fuel and forming a 89 critically low ignition-delay mixture, with a tendency to auto90 ignite in hot charge atmosphere; (v) residue of gas or particles 91 forming hot spots; and (vi) varying pre-ignition characteristics 92 of different fuels. Hence, for a droplet to ignite, there must be a 93 critical amount of heat to initiate the auto-ignition.

94 Several studies ${ }^{9-13}$ have attributed pre-ignition events to the 95 auto-ignition of lubricant oil-fuel mixture droplets. The fuel 96 spray injected into the cylinder has an interaction with the 97 lubricant oil film on the cylinder walls. The splashing of this 98 injected fuel pulls the oil off the wall and forms droplets of the 99 oil-fuel mixture. The interaction with the fuel dilutes the 100 lubricating oil and changes its properties. Therefore, it is 101 important to understand lubricating oils, with and without fuel 102 dilution, as a possible ignition source in pre-ignition and super 103 knock events.

104 By blending ketone (cyclopentanone), alcohol (2-methyl-1105 butanol), and ethylbenzene with gasoline to a $25 \%$ mass 106 fraction, Jatana et al. ${ }^{14}$ found that fuels with similar boiling 107 properties and octane numbers can exhibit similar LSPI 108 number counts but with vastly different LSPI magnitudes and 109 intensities. Kuboyama et al. ${ }^{15}$ visually analyzed the pre-ignition 110 phenomena caused by oil droplets in a highly boosted spark 111 ignition engine. They reported that the mixture of lubricant oil 112 and fuel accumulates in the piston crevice area, which ignites at 113 low oxygen conditions. Fei et al. ${ }^{16}$ found out that within the 114 pressure range of $27-31$ bar, lubricating oil droplet explosion 115 seems to have a positive effect on the amplitude of the pressure 116 oscillation after auto-ignition of the end gas of the ambient mixture. Their finding leads to the conclusion that, at the 117 environmental and initial conditions applied in their study, the 118 lubricating oil droplet does not make an obvious impact on the 119 ignition delay of the combustible ambient gaseous mixture. 120 However, in their study, the lubricating oil is not mixed with 121 the fuel. The possibility of the dilution of the lubrication oil by 122 the fuel was not considered in their work. This may be the 123 reason why the rate of evaporation of the oil droplet in their 124 study is relatively low. In this current study, the possibility of 125 the lubrication dilution by the fuel is the primary 126 consideration.

Previously, Ohtomo et al. ${ }^{10}$ used hexadecane as one of the 128 components for their lubricant oil droplet. Similarly, Distaso et 129 al. ${ }^{17}$ also showed that C16-C18 hydrocarbons could be 130 considered as a surrogate for commercial lubricant oil. 131 Moreover, Kuti et al. ${ }^{18}$ have also reported that hexadecane 132 can reproduce the chemical ignition delay of large alkanes 133 present in lubricant oils. Since $n$-hexadecane $\left(\mathrm{C}_{16} \mathrm{H}_{34}\right)$ has 134 similar ignition characteristics to that of typical lubricant oils, ${ }^{18} 135$ it is considered as a lubricant surrogate in this work. The 136 previous works on the ignition of the droplet in conjunction 137 with the pre-ignition phenomenon can be summarized in 138 Table 1.

Experiments are carried out in a constant volume 140 combustion chamber to study the effects of the RON and 141 MON at varying pressures on time to ignition to generate a 142 better understanding of their influence when blended with 143 lubricating oil at different concentrations. This may be a more 144 representative situation of what is occurring in the actual 145 engine. To study the characteristics of droplet auto-ignition, a 146 single droplet of the hexadecane-fuel mixture is formed and 147 suspended on the bead of a thermocouple located inside the 148 heated vessel. Similar methods have been widely used for 149 studying single droplet combustion. ${ }^{19-21}$ This method has 150 several advantages, which include the ability to record the 151 temperature history of the droplet. The droplet temperature 152 measurement can be considered as a transient bulk temper- 153 ature of the inner droplet since there might be some change in 154 the location of the thermocouple bead inside the droplet 155 during the experiment. ${ }^{20,21}$ Temperature data acquisition is 156 synchronized with high-speed imaging to monitor the droplet 157 combustion process and its temperature evolution in real time. 158

\section{EXPERIMENTAL DETAILS}

The experiments are conducted in a cylindrical constant volume (4 L) 160 combustion chamber (CVCC) (Figure 1), which is designed to study $161 \mathrm{fl}$ 


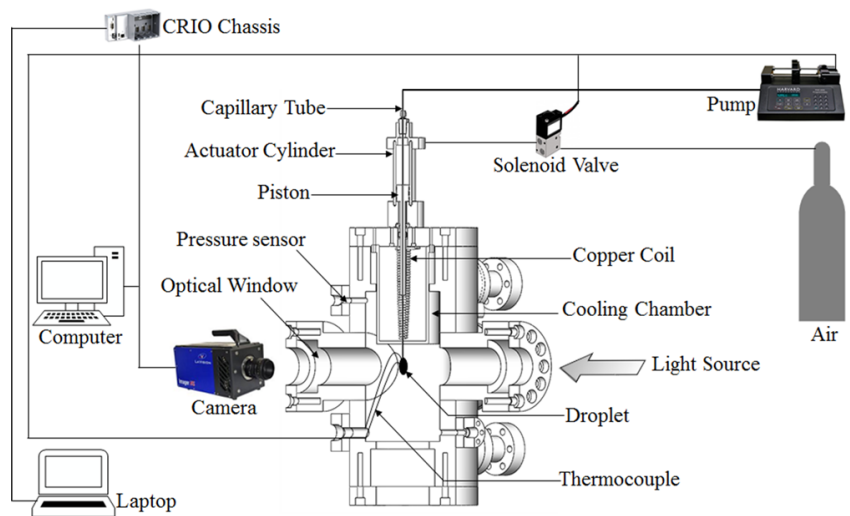

Figure 1. Schematic of the experimental setup with the exaggerated size of the droplet.

162 single droplet ignition phenomena at elevated initial pressures and 163 temperatures. The CVCC is made of stainless steel $316 \mathrm{~L}$ material, 164 and its outer diameter and wall thickness are 320 and $30 \mathrm{~mm}$, 165 respectively. It was pressure tested up to 70 bar via the hydrostatic 166 testing method at room temperature and is capable of operating at $167500{ }^{\circ} \mathrm{C}$. It is equipped with three orthogonal pairs of quartz windows 168 that provide optical access to allow photographic diagnostics of the 169 droplet combustion. An in-line heater (Watlow) with a power rating 170 of $3 \mathrm{~kW}$ and four heating tapes (Omega STH052-100) with a power 171 rating of $0.738 \mathrm{~kW}$ each were installed to heat the chamber to the 172 desired initial temperature.

173 The experiments reported here were carried out in an air 174 environment at an initial temperature of $300 \pm 4{ }^{\circ} \mathrm{C}$ and initial 175 pressures ranging from 4 to $30 \mathrm{bar}$. This temperature was chosen 176 because it was above the auto-ignition temperature of the lubricating 177 oil surrogate but below the auto-ignition temperature of the different 178 diluting fuels. A single droplet injection system was designed and 179 incorporated in the chamber. A capillary tube resides inside a cooling 180 chamber assembly with an actuator system that is water-cooled at 10 $181{ }^{\circ} \mathrm{C}$ and prevents the droplet from evaporating or igniting before it is 182 suspended on the K-type thermocouple bead. This allows us to 183 monitor the droplet lifetime temperature from its time of suspension 184 until it is completely consumed. The hexadecane-fuel mixture is 185 delivered to the capillary tube via a syringe pump (Harvard Apparatus 186 PHD 2000). The piston's movement inside the actuator cylinder is 187 controlled by pneumatic solenoid valves (Peter Paul Electronics Co., 188 EH22H90CCH6).

189 A high-speed camera (PCO, Imager Pro HS, 4M) is used for 190 recording the process from the suspension of the droplet on the 191 thermocouple bead until its auto-ignition utilizing a shadowgraph 192 technique at the frame rate of $500 \mathrm{fps}$. A LabVIEW-based program is 193 designed to synchronize the activation of the syringe pump for 194 injecting the mixture, the extension, and retraction of the actuator's 195 piston holding the capillary tube, the triggering of the camera, and the 196 temperature data acquisition. The extension of the piston, the camera 197 trigger, and the start of temperature data acquisition are started at the 198 same time. This is immediately followed by the activation of the 199 syringe pump to inject the hexadecane-fuel mixture to form a droplet 200 on the thermocouple bead.

201 The time duration for the extension and residence time of the 202 capillary tube in the hot environment is set at $1 \mathrm{~s}$ each. This is to 203 avoid a longer exposure of the capillary tube to the hot environment 204 inside the vessel that could trigger the early ignition of the 205 hexadecane-fuel mixture before the suspension of the droplet. After 206 the hexadecane-fuel mixture droplet is suspended on the bead of the 207 thermocouple, the piston is retracted to the cooling chamber. The 208 time duration for the temperature data acquisition is set such that the 209 suspension, auto-ignition of the droplet, and complete burnout of the 210 droplet are recorded.

211 A precise syringe pump with an accuracy of $\pm 1 \%$ and 212 reproducibility of $\pm 0.1 \%$ was used to inject the same amount of the mixture during the droplet generation every test. In combination with 213 the developed automation system to record the data and control the 214 injected quantity, the data collected from at least 10 trials for each 215 running condition were averaged. This leads to good repeatability and 216 high accuracy in maintaining the amount of the injected mixture. 217 Therefore, despite the shape of the droplet that is not complete 218 spherical, the time to ignition (TI) recorded from every test was based 219 on the same quantity of the injected mixture. Several preliminary tests 220 had been carried out to find the suitable position of the thermocouple 221 relative to the injection needle to suspend the droplet on the 222 thermocouple bead. The inclination angle of the thermocouple was 223 set such that the amount of the mixture injected is sufficient to form a 224 droplet, which is very close to the sphere in shape. If the amount of 225 the injected mixture is very less, the droplet cannot be suspended as 226 the amount of the mixture will only create a thin coating on the 227 thermocouple wire. On the other hand, if the amount of the mixture 228 injected is too much, the droplet will not be suspended as it will drop 229 immediately due to its weight; these observations were also reported 230 during the suspension of the droplet of highly viscous heavy fuel oil 231 on the thermocouple bead. ${ }^{22}$ Due to this, the combination of the 232 inclination angle of the thermocouple wire and the amount of the 233 mixture injected has to be defined carefully so the droplet can be 234 suspended on the thermocouple bead.

The baseline case of this study for the pre-ignition was done by 236 suspending a droplet of pure hexadecane, the lubricating oil surrogate 237 without fuel dilution. To study the effect of the interaction between 238 the oil and the fuel, hexadecane was mixed with FACE-I, PRF-91, 239 PRF-95, and toluene individually, which have the octane number of 240 $70,91,95$, and 120, respectively (see Table 2). Relevant properties of $241 \mathrm{t} 2 \mathrm{t} 3$

\section{Table 2. Matrix for Tested Fuels}

\begin{tabular}{|c|c|c|c|c|}
\hline $\begin{array}{l}\text { hexadecane } \\
\text { (vol \%) }\end{array}$ & $\begin{array}{c}\text { FACE-I } \\
(\mathrm{RON}=70) \\
(\text { vol \%) }\end{array}$ & $\begin{array}{c}\text { PRF-91 } \\
(\text { RON = 91) } \\
(\text { vol \% })\end{array}$ & $\begin{array}{c}\text { PRF-95 } \\
(\text { RON = 95) } \\
(\text { vol \%) }\end{array}$ & $\begin{array}{c}\text { toluene } \\
(\mathrm{RON}=120) \\
(\operatorname{vol} \%)\end{array}$ \\
\hline \multicolumn{5}{|l|}{100} \\
\hline 75 & 25 & & & \\
\hline 75 & & 25 & & \\
\hline 75 & & & 25 & \\
\hline 75 & & & & 25 \\
\hline
\end{tabular}

hexadecane and fuels used are listed in Table 3. The boiling point, $242 \mathrm{t} 3$ flash point, and autoignition temperature of PRF-91 and PRF-95 243 presented in Table 3 are estimated based on the ratio of the mixture 244 of isooctane and $n$-heptane.

245

To assess the effect of diluting fuel's RON to its ignition behavior, 246 pure air was used in the current study. Since the auto-ignition 247 temperature of hexadecane is lower than those of fuels, the presence 248 of the volume fraction of fuel in the hexadecane-fuel mixture is 249 expected to delay the process of droplet ignition. The temperature of 250 the vessel was set at $300 \pm 4{ }^{\circ} \mathrm{C}$, so it was higher than the autoignition 251 temperature of hexadecane, but it is lower than that of the fuels used. 252 The tests were carried out for different pressures, while the 253 temperature was maintained constant at $300 \pm 4{ }^{\circ} \mathrm{C}$. The time to 254 ignition (TI) of the droplet recorded from the suspension of the 255 droplet until it ignited was plotted against different ambient pressures. 256

\section{RESULTS AND DISCUSSIONS}

The typical temperature history of the droplet ignition is 258 shown in Figure 2, together with snapshots of the droplet from $259 \mathrm{f} 2$ the initial injection of the mixture onto the thermocouple bead 260 till the end of the combustion phase. The thick black line 261 represents the average temperature of 10 independent 262 experiments with a $1.6 \mathrm{~mm}$ diameter droplet of 75 vol $\% n-263$ hexadecane and $25 \mathrm{vol} \%$ toluene in the air at $300 \pm 4{ }^{\circ} \mathrm{C}$ and 264 10 bar pressure. The gray vertical fringe at the background 265 represents the standard deviation of these experimental data. 266 
Table 3. Properties of Hexadecane, Isooctane, $\boldsymbol{n}$-Heptane, Toluene, and FACE-I

$\begin{array}{cllllrc}\text { no. } & \text { chemicals } & \text { boiling point }\left({ }^{\circ} \mathrm{C}\right) & \text { flash point }\left({ }^{\circ} \mathrm{C}\right) & \text { auto-ignition }\left({ }^{\circ} \mathrm{C}\right) & \mathrm{RON} & -263.5 \\ 1 & \text { hexadecane } & 286.9 & 135 & 202 & 105 \\ 2 & \text { isooctane } & 117.72 & -12.22 & 215 & 100 \\ 3 & n \text {-heptane } & 98.38 & -3.88 & 480 & 0 & 54.16 \\ 4 & \text { toluene } & 110.6 & 6 & 426.1 \text { (estimated) } & 120 \\ 5 & \text { PRF-91 } & 116.0 \text { (estimated) } & -11.5 \text { (estimated) } & 91 & 6 \\ 6 & \text { PRF-95 } & 116.8 \text { (estimated) } & -11.8 \text { (estimated) } & 435.4 \text { (estimated) } & 95 \\ 7 & \text { FACE-I } & 37.5-123 & \mathrm{NA}^{a} & \text { NA } & 70.57 \\ \end{array}$

${ }^{a} \mathrm{NA}$, not applicable.

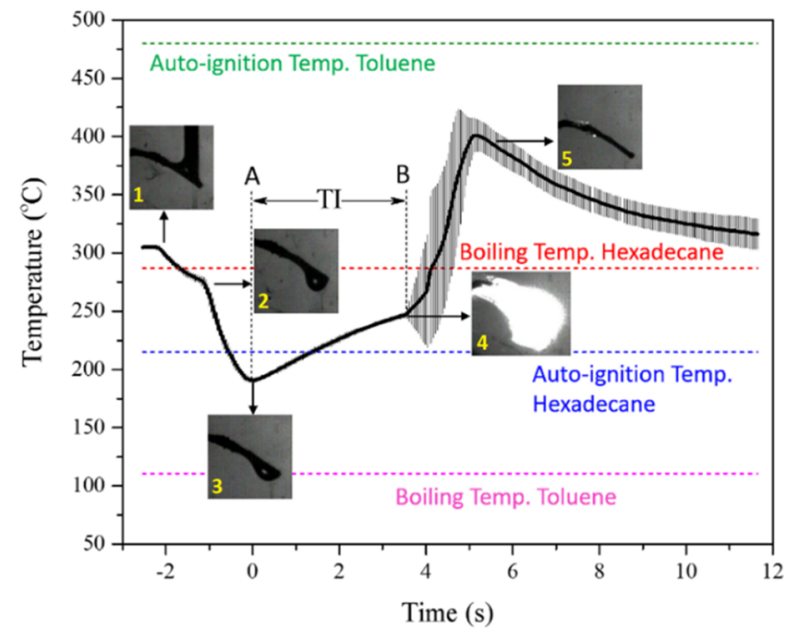

Figure 2. Temperature history of pre-ignition event of the $75 \%$ volume fraction of hexadecane $+25 \%$ volume fraction of toluene at a pressure of 10 bar.

267 The process of the suspension, evaporation, and ignition of the 268 droplet mixture can be elaborated as follows:

1. Image 1 shows the dripping of the hexadecane-toluene mixture from the capillary tube. It is evident that, as soon as the hexadecane-toluene mixture touches the thermocouple bead, the temperature drops gradually (recall that the mixture is held in a low-temperature zone until injected).

2. Image 2 shows the droplet successfully suspended on the thermocouple bead. It is shown in the temperature history that the decrease in temperature becomes steeper after the droplet is successfully suspended.

3. Image 3 shows the start of the droplet evaporation that coincides with point $\mathrm{A}$ where the minimum temperature is reached in the temperature history. Heat transferred from the hot surroundings toward the droplets results in the evaporation of the droplet. Internal conduction results in the interior of the droplet, also increasing in temperature. As evaporation occurs, the hexadecanetoluene mixture vapor diffuses into the hot ambient air.

4. Image 4 shows the start ignition of the droplet. One of the primary characteristics of droplet ignition under high-pressure conditions is the Stefan flow of fuel vapor from the droplet surface that is slow due to the increase in boiling temperature and the decrease in diffusion coefficient. ${ }^{23}$ The ignition is followed by a steep increase in the temperature until it reaches its maximum, after which the flame started to diminish.

5. Image 5 shows the condition where the flame has completely consumed all the oil-fuel mixture. This is followed by the gradual decrease in temperature until it 297 reaches near ambient. The energy liberated by the 298 combustion of the oil-fuel droplet is small compared 299 with the heat capacity of the ambient air, so little change 300 in bulk temperature is observed.

301

Unlike the work done by Fei et al. ${ }^{16}$ the tests in the current 302 work demonstrated that the presence of fuel in the hexadecane 303 mixture increases the evaporation rate of its droplet. The vapor 304 of the mixture then mixed with the hot ambient air and formed 305 a combustible mixture from which the ignition of the droplet is 306 triggered. Figure 2 also shows the auto-ignition temperatures 307 of hexadecane and toluene. While the auto-ignition temper- 308 ature of hexadecane is lower than that of toluene, its boiling 309 temperature is higher than that of toluene. Therefore, mixing 310 with toluene will result in a lower boiling temperature than that 311 of pure hexadecane.

Consequently, the evaporation rate of the hexadecane- 313 toluene mixture is higher than that of pure hexadecane. On the 314 other hand, since the auto-ignition temperature of toluene is 315 higher than that of hexadecane, it causes the auto-ignition 316 temperature of the hexadecane-toluene mixture to be higher 317 than that of pure hexadecane. As a result, the presence of 318 toluene increases the evaporation rate of the mixture, but the 319 time to ignition of the hexadecane-toluene mixture is longer 320 than that of pure hexadecane.

321

The series of pictures that show the evaluation of the 322 evaporation of the droplet before its ignition is presented in 323 Figure 3 for hexadecane mixed with FACE-I, PRF-91, PRF-95, $324 \mathrm{f} 3$ and toluene. In these images, it is clearly shown that the auto- 325 ignition of the droplet is proceeded by droplet evaporation. It 326 is also evident from Figure 3 that, for the hexadecane-FACE-I 327 mixture, the ignition occurred when the droplet is still partly 328 visible. While for the mixture with PRF-91, PRF-95, and 329 toluene, the ignition occurred when the droplet is not visible 330 anymore. This condition suggests that the entrapment of a 331 more volatile component within the heated droplet could lead 332 to the fragmentation of droplet due to the internal pressure 333 build up. ${ }^{24}$

Using the plot presented in Figure 2, the time for the droplet 335 to ignite, TI, is defined as the time interval between the 336 minimum temperatures (A) until the time where the ignition 337 of the droplet is first obvious (B). Point B is indicated by the 338 sudden increase in $\frac{\mathrm{d} T}{\mathrm{~d} t}$ in the temperature history. The TI 339 describes the time needed for the droplet to be heated and 340 evaporated, and its vapor mixes with the hot ambient air to 341 form the combustible mixture that can ignite. To verify this, 342 the plot of $\frac{\mathrm{d} T}{\mathrm{~d} t}$ of the hexadecane-PRF95 mixture is super- 343 imposed on its temperature history data and presented in 344 Figure 4. Based on the series of images in Figure 3c, which $345 \mathrm{f} 4$ 


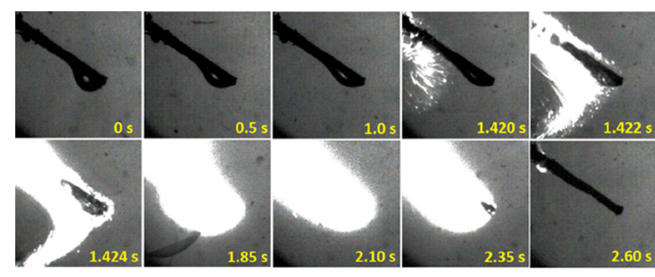

(a) $75 \%$ Hexadecane $+25 \%$ Face-I $(\mathrm{RON}=180.13)$

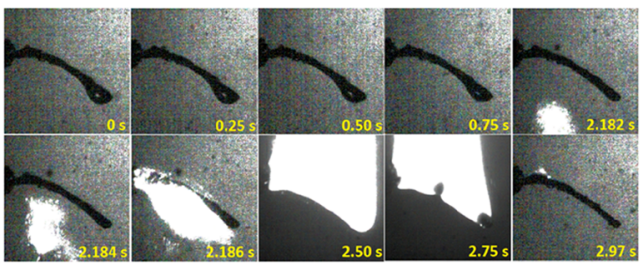

(b) $75 \%$ Hexadecane $+25 \%$ PRF-91 $(\mathrm{RON}=-174.88)$

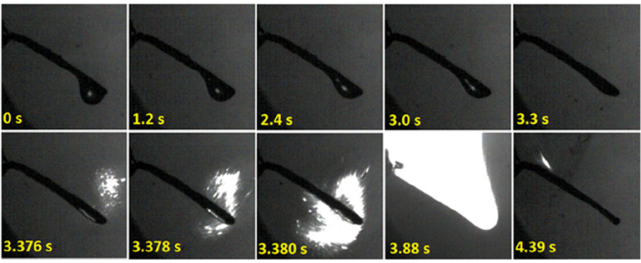

(c) $75 \%$ Hexadecane $+25 \%$ PRF95 $(\mathrm{RON}=-173.88)$

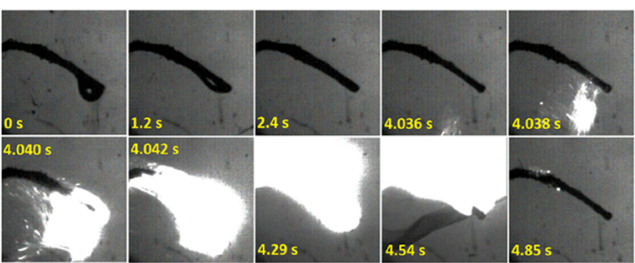

(d) $75 \%$ Hexadecane $+25 \%$ Toluene $(\mathrm{RON}=-167.63)$

Figure 3. Process ignition of the droplet at $P=10 \mathrm{bar}$.

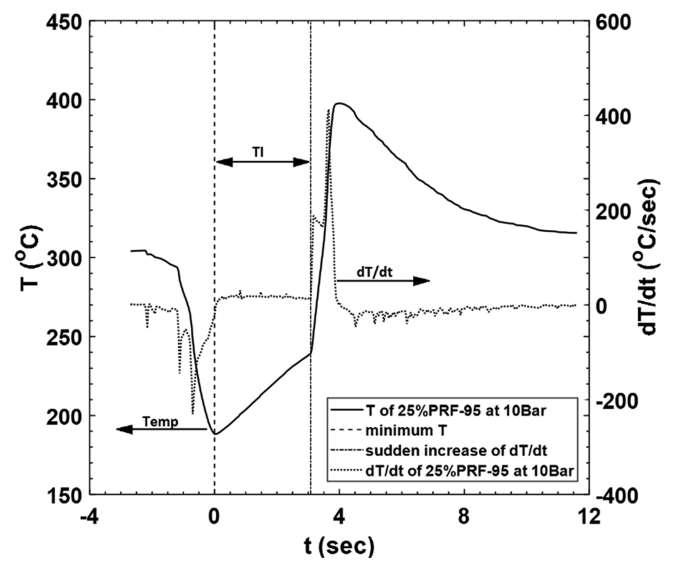

Figure 4. Temperature history of the hexadecane-PRF95 mixture and its $\frac{\mathrm{d} T}{\mathrm{~d} t}$ at 10 bar.

346 shows the process of ignition of the hexadecane/PRF-95 347 droplet, the ignition was triggered at about $3.38 \mathrm{~s}$ after the 348 droplet was suspended on the thermocouple. By making the 349 vertical black dashed-dotted line, it is evident that this timing ${ }_{350}$ coincides with the sudden increase in $\frac{\mathrm{d} T}{\mathrm{~d} t}$ where the droplet 351 started to ignite. Accordingly, in Figure 4, the TI is defined as the time interval between the dashed line and dashed-dotted 352 line.

To investigate the effect of the pressure on the time of 354 droplet ignition, TI, the temperature history of the 355 hexadecane-PRF-95 droplet mixture at pressures of 4, 10, 356 and 22 bar are presented in Figure 5. It is evident that the $357 \mathrm{fs}$

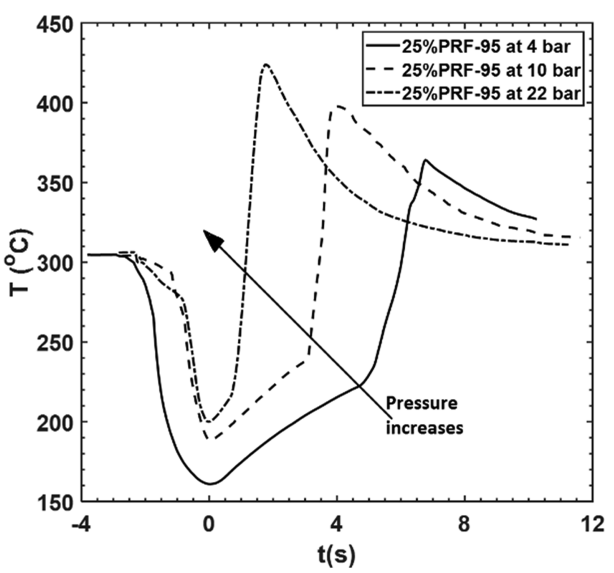

Figure 5. Temperature history of the hexadecane-PRF95 mixture at 4, 10 , and 22 bar.

temperature gradient, at the point where the droplet's 358 temperature is minimum, for the pressure of 4 bar is initially 359 comparable to that of 10 and 22 bar. As the temperature starts 360 increasing from its minimum, the gradient at 4 bar increases 361 more slowly compared with those lower than those of 10 and 362 22 bar.

To show the variation of evaporation rate, the time history 364 of $\frac{\mathrm{d} T}{\mathrm{~d} t}$ for the hexadecane-PRF-95 mixture at the pressure of 4, 365 10, and 22 bar was superimposed and is presented in Figure 6. $366 \mathrm{fo}$ It is evident that the rate increase in temperature $\left(\frac{\mathrm{d} T}{\mathrm{~d} t}\right)$ from the ${ }_{367}$ point where the temperature is minimum (A), increases with 368 the increased pressure. Since for all liquids, the coefficient of 369 the thermal conductivity increases with pressure, it suggests 370 that the heat transfer in the current work is dominated by 371 conduction. Consequently, the formation of the combustible 372 mixture between the vapor of the hexadecane-PRF95 mixture 373 with the ambient air at a low pressure needs a longer time to 374 approach the minimum mixture flammability limit. Thus, 375 increasing pressure of the vessel at constant ambient 376 temperature expedites the auto-ignition of the mixture, which 377 leads to the decrease in TI with the increase in the pressure as 378 shown in Figure 5.

To study the role of the fuel's RON at different pressures, 380 the RON is a nondimensional parameter, so TI and $P$ are 381 normalized to make it nondimensional too. The normalized TI 382 $\left(\mathrm{TI}^{*}\right)$ is obtained by normalizing the TI of each mixture at 383 each pressure $\left(\mathrm{TI}_{i}\right)$ with the TI of pure hexadecane obtained at 384 a pressure of 4 bar $\left(\mathrm{TI}^{*}=\frac{\mathrm{TI}_{i}}{\mathrm{TI}_{\mathrm{Hex}-4 \mathrm{bar}}}\right)$. The nondimensionalized ${ }_{385}$ pressure $\left(P^{*}\right)$ is the vessel pressure normalized by the 386 atmospheric pressure $\left(P^{*}=\frac{P}{P_{\text {atm }}}\right)$.

The RON of the hexadecane-fuel mixture is estimated using 388 the following correlation ${ }^{25}$

$$
\mathrm{RON}_{\text {mix }}=\sum_{i}\left(x_{i} \cdot \mathrm{RON}_{i}\right)
$$



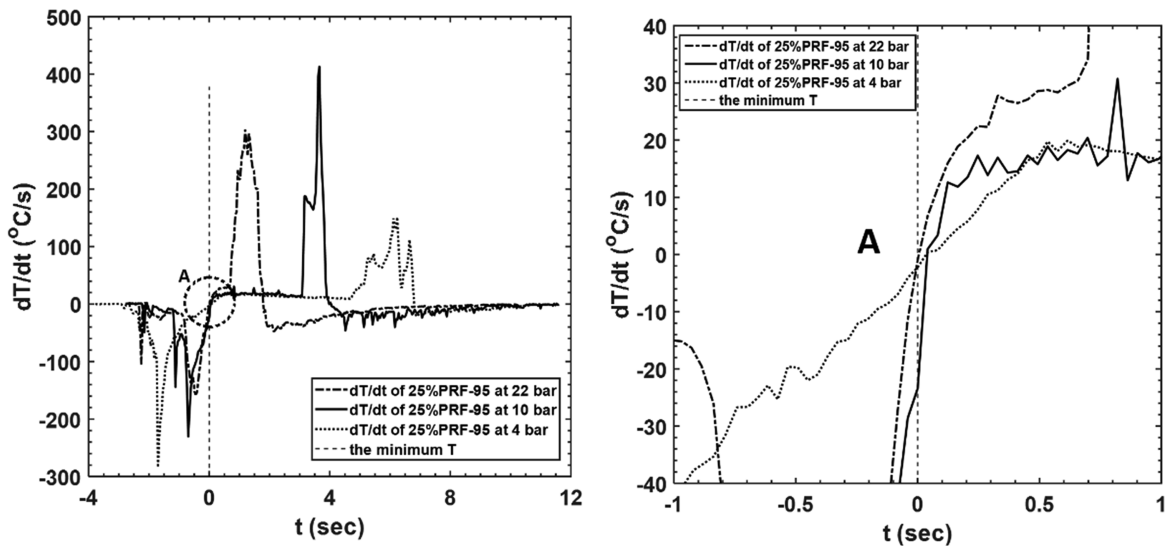

Figure 6. (a) Comparison of a $\frac{d T}{d t}$ of the hexadecane-PRF95 mixture for the vessel pressure of 4, 10, and 22 bar. (b) Zoom-in view of $\frac{d T}{d t}$.

391 where $x_{i}$ is the volume fraction of the $i$ component in the 392 mixture, and $\mathrm{RON}_{i}$ is the RON of the individual components. 393 The RON of hexadecane is estimated using a derived cetane 394 number $(\mathrm{DCN}) .^{26}$

395

$$
\mathrm{RON}=-293\left(\frac{\mathrm{DCN}}{100}\right)^{2}-52\left(\frac{\mathrm{DCN}}{100}\right)+114.1
$$

396 According to Kubic, ${ }^{27}$ the DCN is a biased estimate of the 397 cetane number $(\mathrm{CN})$. Using the $\mathrm{DCN}-\mathrm{CN}$ relation provided 398 by Kubic, ${ }^{27}$ the hexadecane's RON could be evaluated. They 399 showed that the $\mathrm{CN}$ of 100 (that is the cetane number of 400 hexadecane) corresponds to a DCN of 105. Using this DCN, 401 the RON of hexadecane can be estimated as follows:

$$
\mathrm{RON}=-293\left(\frac{105}{100}\right)^{2}-52\left(\frac{105}{100}\right)+114.1=-263.5
$$

402

403 To verify this, estimated RON of hexadecane, the structural 404 group contribution method ${ }^{27,28}$ is used, which is expressed as 405 follows

406

$$
\begin{aligned}
\mathrm{RON}= & a+b\left\{\sum_{i}(\mathrm{ON})_{i}\right\}+c\left\{\sum_{i}(\mathrm{ON})_{i}^{2}\right\} \\
& +d\left\{\sum_{i}(\mathrm{ON})_{i}^{3}\right\}+e\left\{\sum_{i}(\mathrm{ON})_{i}^{4}\right\} \\
& +f\left\{\sum_{i}(\mathrm{ON})_{i}\right\}
\end{aligned}
$$

407 where $\sum_{i}(\mathrm{ON})_{i}$ is the sum of the group contributions for the 408 RON obtained from Table 4 , and $a, b, c, d, e$, and $f$ are 409 correlation constants from Table 5.

410 From the molecular structure of hexadecane, there are two 411 groups of $\left(-\mathrm{CH}_{3}\right)$ and 14 groups of $\left(>\mathrm{CH}_{2}\right)$. Accordingly, the $\sum_{i}(\mathrm{ON})_{i}$ for hexadecane is -122.902 . Using eq 3 , the RON of 412 hexadecane can be estimated as follows:

$$
\begin{aligned}
\mathrm{RON}= & 103.6+0.231\{-122.902\}+(-0.0226) \\
& \left\{(-122.902)^{2}\right\} \\
= & -266.2
\end{aligned}
$$

\begin{tabular}{|c|c|c|c|}
\hline type of hydrocarbon & serial number & group & $(\mathrm{ON})_{i}$ \\
\hline \multirow[t]{4}{*}{ paraffins } & 1 & $-\mathrm{CH}_{3}$ & -2.315 \\
\hline & 2 & $>\mathrm{CH}_{2}$ & -8.448 \\
\hline & 3 & $>\mathrm{CH}-$ & -0.176 \\
\hline & 4 & $>\mathrm{C}<$ & 11.94 \\
\hline \multirow[t]{8}{*}{ olefins } & 5 & $=\mathrm{CH}-$ & 0.392 \\
\hline & 6 & $>\mathrm{C}=$ & 8.697 \\
\hline & 7 & $=\mathrm{CH}_{2}$ & 3.623 \\
\hline & 8 & $=\mathrm{C}=$ & -37.37 \\
\hline & 9 & $=\mathrm{CH}-{ }_{(\mathrm{cis})}$ & 6.269 \\
\hline & 10 & $=\mathrm{CH}-{ }_{\text {(trans) }}$ & 6.449 \\
\hline & 11 & $\equiv \mathrm{CH}$ & 18.36 \\
\hline & 12 & $\equiv \mathrm{C}-$ & -7.201 \\
\hline \multirow[t]{5}{*}{ cyclic $^{a}$} & 13 & $>\mathrm{CH}_{2}$ & -4.421 \\
\hline & 14 & $>\mathrm{CH}-$ & -2.177 \\
\hline & 15 & $>\mathrm{C}<$ & 8.916 \\
\hline & 16 & $=\mathrm{CH}-$ & 2.879 \\
\hline & 17 & $>\mathrm{C}=$ & 5.409 \\
\hline \multirow[t]{5}{*}{$\operatorname{aromatics}^{a}$} & 18 & $=\mathrm{CH}-$ & 3.591 \\
\hline & 19 & $>\mathrm{C}=$ & 2.382 \\
\hline & 20 & $>\mathrm{C}={ }_{(0)}$ & -1.768 \\
\hline & 21 & $>\mathrm{C}={ }_{(\mathrm{m})}$ & 10.24 \\
\hline & 22 & $>\mathrm{C}={ }_{(\mathrm{p})}$ & 11.51 \\
\hline
\end{tabular}

414 Based on the calculation shown in eqs $2 \mathrm{a}$ and $3 \mathrm{a}$, it is found 415 that eqs 2 and 3 give a comparable result for the estimation of
Table 4. Group Contribution for Estimation of the Hydrocarbon's Octane Number ${ }^{28}$

${ }^{a}$ Groups $19-22$ are all nonfused.

the RON of hexadecane. For the current work, the estimated 416 RON of hexadecane obtained from eq 2 will be used for 417 calculating the RON of the different hexadecane-fuel mixtures. 418 After employing eqs 1 and 2, the RON of the reactants and 419 mixtures used can be estimated and tabulated in Table $6 . \quad 420$ t6

Based on the RON of the mixtures presented in Table 6 , the 421 plot of $P^{*}$ against TI* is shown in Figure 7 for the different oil- $422 \mathrm{f} 7$ fuel mixtures. It is apparent from Figure 7 that the addition of 423 the aforementioned fuels in hexadecane has significantly 424 increased the $\mathrm{TI}^{*}$ of the oil-fuel droplet. For all of the 425 mixtures investigated, the TI decreases exponentially with 426 increasing pressure. It is worth noting the significant increase 427 in the $\mathrm{TI}^{*}$ for $P^{*}$ lower than 16 , while a very small change in 428 the $\mathrm{TI}^{*}$ is shown at $P^{*}$ higher than 20 , showing an asymptotic 429 behavior. 430

To deduce an empirical relationship for $\mathrm{TI}^{*}=f\left(\mathrm{RON}, P^{*}\right), 431$ curve fitting of the experimental data are plotted in Figure $7 a-432$ 
Table 5. Correlation Constant for eq $2^{28}$

\begin{tabular}{cccccccc} 
octane number & $a$ & $b$ & $c$ & & $d$ & \\
RON & 103.6 & 0.231 & -0.0226 & 0.001 & $1.42 \times 10^{-05}$ & & \\
MON & 88.87 & 0.212 & -0.0093 & 0.00104 & $9.59 \times 10^{-06}$ \\
\hline
\end{tabular}

Table 6. RON of Reactants and Mixtures

\begin{tabular}{lc}
\multicolumn{1}{c}{ reactants/mixtures } & RON \\
hexadecane & -263.5 \\
FACE-I & 70 \\
PRF-91 & 91 \\
PRF-95 & 95 \\
toluene & 120 \\
$75 \%$ hexadecane $+25 \%$ FACE-I & -180.125 \\
$75 \%$ hexadecane $+25 \%$ PRF-91 & -174.875 \\
$75 \%$ hexadecane $+25 \%$ PRF-95 & -173.875 \\
$75 \%$ hexadecane $+25 \%$ toluene & -167.625
\end{tabular}

$433 \mathrm{~d}$. These fits can be represented by the exponential model as 434 follows:

$$
435 \quad \mathrm{TI}^{*}=a \cdot \mathrm{e}^{\left(b \cdot P^{*}\right)}
$$

436 In this equation, $a=f(\mathrm{RON})$, and $b=f\left(P^{*}\right)$. Using the log 437 scale in the $y$ axis, the line fit of hexadecane-fuel mixture's TI* 438 data in Figure 7 can be represented as five parallel straight lines 439 with the same gradient (Figure 8). Referring to eq 4, the value 440 of $a$ represents the interception of each line with the $y$ axis, 441 while $b$ is the slope of the lines. The values of $a$ and $b$ can be 442 tabulated as shown in Table 7.

443 As presented in Table 7 , the value of " $a$ " varies with the 444 RON, while " $b$ " is invariant. By carrying out the exponential fit

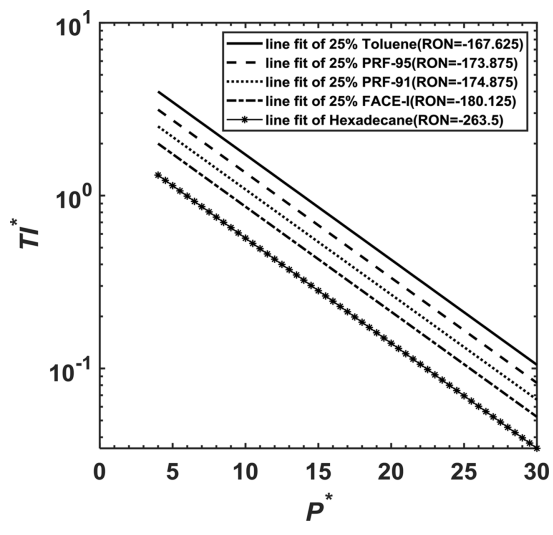

Figure 8. Line fit of the TI data in the log scale.

to the data of " $a$ " against the RON of the mixture (Figure 9), $445 \mathrm{fg}$ the correlation between " $a$ " and the RON can be expressed as 446

$$
a=2+18,000 \times \mathrm{e}^{0.05(\mathrm{RON})}
$$

By substituting eq 5 into eq 4, the final empirical model for 448 showing $\mathrm{TI}^{*}=f\left(\mathrm{RON}, P^{*}\right)$ can be presented as follows: $\quad 449$

$$
\mathrm{TI}^{*}=2 \times \mathrm{e}^{-0.14\left(P^{*}\right)}\left[1+9000 \times \mathrm{e}^{0.05(\mathrm{RON})}\right] \quad \text { (6) } 450
$$
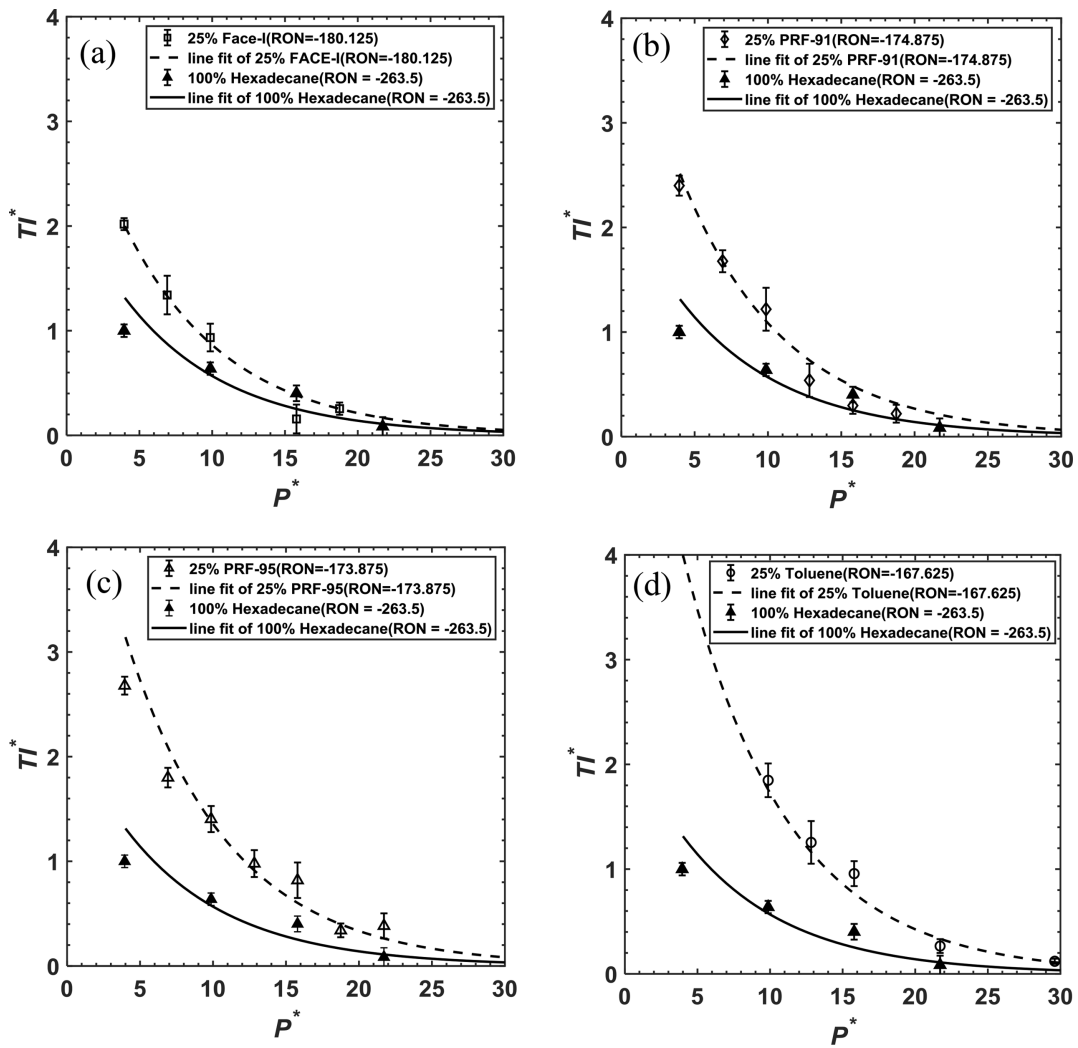

Figure 7. TI* distribution of hexadecane-fuel mixtures against $P^{*}$ (a) $75 \%$ hexadecane $+25 \%$ FACE-I, (b) $75 \%$ hexadecane $+25 \%$ PRF-91, (c) $75 \%$ hexadecane $+25 \%$ PRF-95, and (d) $75 \%$ hexadecane $+25 \%$ toluene. 
Table 7. Tabulation of the Values of $a$ and $b$ from eq 4 for each RON of the Mixture

\begin{tabular}{lcccc}
\multicolumn{1}{c}{ mixtures } & RON & $\begin{array}{c}\text { DCN (calculated } \\
\text { using eq 2) }\end{array}$ & $a$ & $b$ \\
\hline $100 \%$ hexadecane & -263.50 & 105.00 & 2.3 & -0.14 \\
$75 \%$ hexadecane $+25 \%$ & -180.13 & 91.73 & 3.5 & -0.14 \\
$\quad$ FACE-I & & & & \\
$75 \%$ hexadecane $+25 \%$ & -174.88 & 90.83 & 4.4 & -0.14 \\
PRF-91 & & 90.66 & 5.5 & -0.14 \\
$\begin{array}{l}75 \% \text { hexadecane }+25 \% \\
\text { PRF-95 }\end{array}$ & -173.88 & & & \\
$\begin{array}{l}\text { 75\% hexadecane }+25 \% \\
\text { toluene }\end{array}$ & -167.63 & 89.58 & 7.5 & -0.14 \\
\end{tabular}

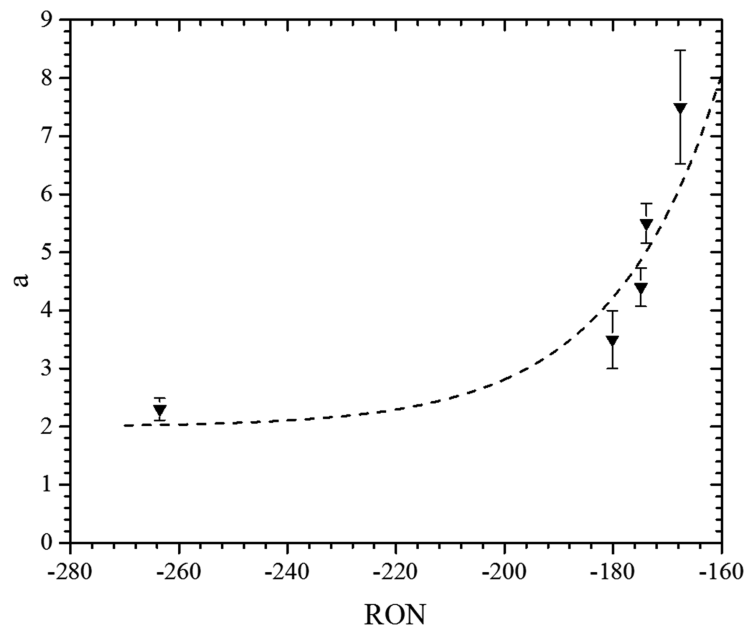

Figure 9. Data plotting of $a$ parameter versus RON.

451 This empirical model shows the dependence of the TI* of 452 the mixtures to $P^{*}$ and its $\mathrm{RON}$ for a $25 \%$ volume fraction of 453 fuels mixed with a $75 \%$ volume fraction of hexadecane 454 (lubricating oil surrogate). To visualize this correlation, a 3D 455 plot of this equation model is presented in Figure $10 . \mathrm{TI}^{*}$

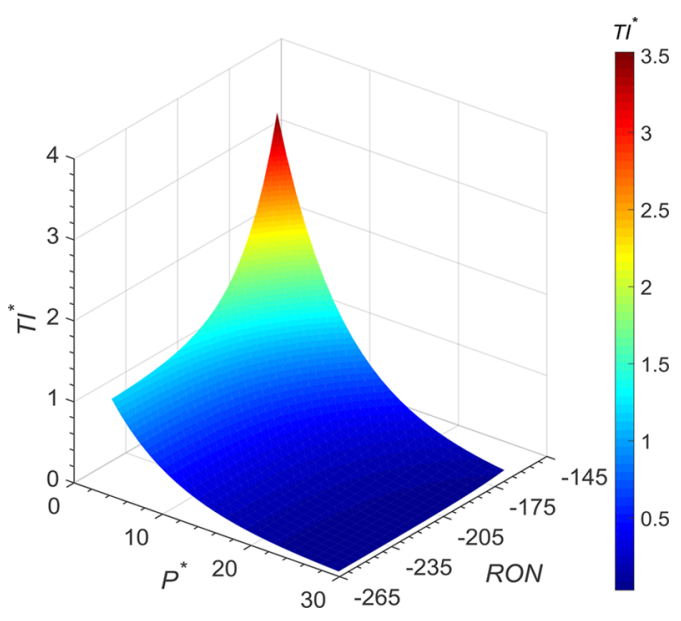

Figure 10. $3 \mathrm{D}$ plot of $\mathrm{TI}^{*}=f\left(\mathrm{RON}, P^{*}\right)$.

456 contours presented in Figure 10 suggest that the use of a high 457 RON fuel at the pressure range higher than 20 bar has an 458 insignificant effect on enhancing or suppressing the auto459 ignition of hexadecane-fuel mixture's droplet. This is indicated 460 by the TI, which is invariant with increasing the RON of the 461 fuels.
By plotting the TI* data obtained at the vessel pressures of 462 4,10 , and 22 bar against the empirical line fit (Figure 11), it is $463 \mathrm{fl} 1$

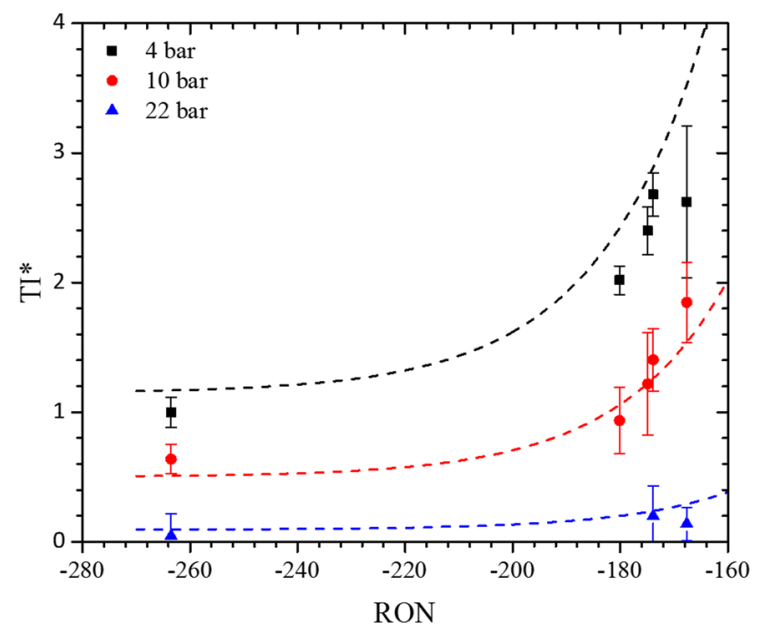

Figure 11. Plot of the $\mathrm{TI}^{*}$ as a function of the RON at the vessel pressures of 4,10 , and 22 bar.

evident that the TI of the mixture increases exponentially with 464 increasing the mixture's RON. A plausible explanation of this 465 phenomenon is based on the fact that the RON is a measure of 466 auto-ignition or anti-knock quality of a fuel, which affect the 467 ignition delay time. Therefore, in the current study, the auto- 468 ignition or anti-knock quality of the mixture has been 469 improved as the fuel's RON of the fuel mixed with hexadecane 470 is increased. It results in an increase in TI as the fuel's RON 471 increases. These results agree with those reported by 472 Kalghatgi $^{29}$ who studied the auto-ignition of practical fuels 473 and found that fuels in the gasoline auto-ignition range, $\mathrm{RON} 474$ $>60$ and $\mathrm{DCN}<30$, have relatively long ignition delay. 475

It is also demonstrated in Figure 11 that the empirical model 476 agrees very well with the experimental data at pressures of 10477 and 22 bar, while at a pressure of 4 bar, the empirical model 478 slightly overestimated the TI. Nevertheless, the empirical 479 model can show the trend of the data at 4 bar. It is also shown 480 that, as the pressure increases, the difference of the TI for 481 different RONs becomes smaller. This suggests that the effect 482 of the fuel's RON in delaying the auto-ignition of lubricating 483 oil-fuel droplets diminishes with increasing pressure. In other 484 words, the current study shows that in the high-pressure 485 regime ( $>20$ bar), the dilution of lubricating oil surrogate due 486 to the mixing with different fuels (and hence different RONs), 487 at a $25 \%$ volume fraction, does not delay the auto-ignition of 488 the droplet significantly.

489

To show the correlation between the mixture DCN and TI*, 490 data have been plotted to initially find the correlation between 491 the DCN and the constant " $a$ ". As presented in Figure 12, the $492 \mathrm{f} 12$ correlation between the DCN and " $a$ " can be expressed as 493

$$
a=2.25 \times\left\{1+5 \times 10^{23} \times \mathrm{e}^{(-0.6 \times \mathrm{DCN})}\right\}
$$

It is very obvious that the empirical function presented in eq 495 7 shows good agreement with the experimental data. By 496 substituting this equation into eq 4 , the correlation between 497 the $\mathrm{TI}^{*}$ and $\mathrm{DCN}$ can be expressed as:

$$
\mathrm{TI}^{*}=2.25 \times \mathrm{e}^{\left(-0.4 \times P^{*}\right)} \times\left\{1+5 \times 10^{23} \times \mathrm{e}^{(-0.6 \times \mathrm{DCN})}\right\}
$$




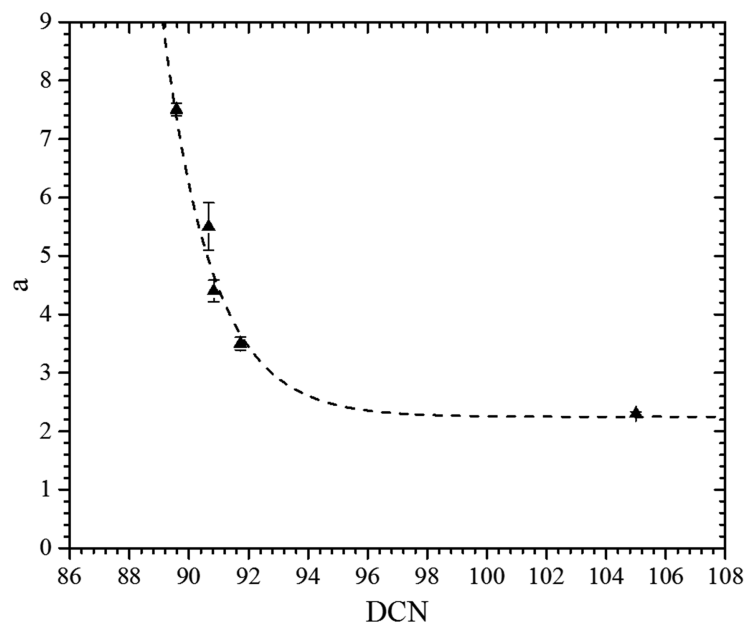

Figure 12. Data plotting of a parameter versus DCN.

500 Figure 13 shows that the empirical function presented in eq 5018 agrees well with the experimental data from the current 502 study.

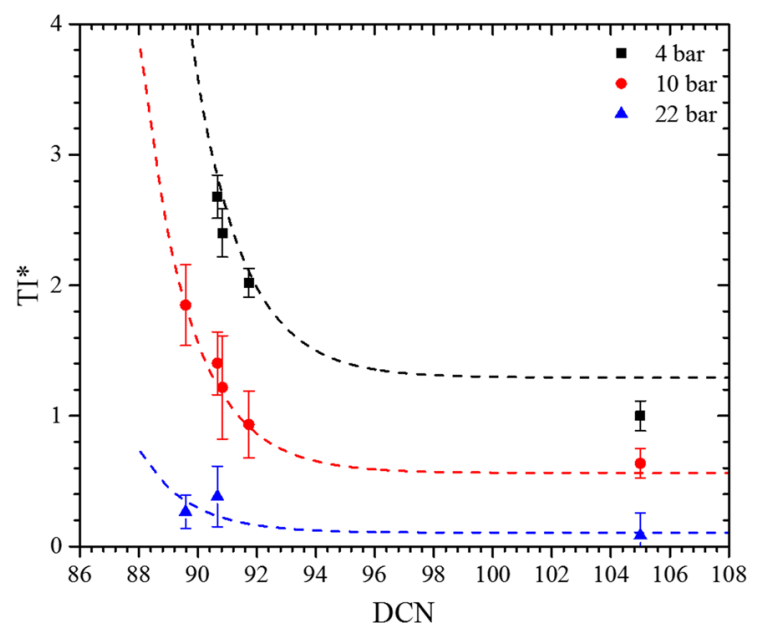

Figure 13. Plot of the $\mathrm{TI}^{*}$ as the function of the $\mathrm{DCN}$ at the vessel pressures of 4,10 , and 22 bar.

\section{${ }_{503}$ CONCLUSIONS}

504 A study of the auto-ignition of a single droplet of a lubricating 505 oil surrogate (hexadecane) diluted with different fuels at a 506 mixture ratio of $3: 1$ at an ambient temperature of $300 \pm 4{ }^{\circ} \mathrm{C}$ 507 has been carried out over a range of initial pressures. The 508 temperature difference between the "cold" droplet and the hot 509 ambient air results in heat transfer into the droplet. Some 510 hexadecane-fuel mixture will evaporate and mix with the 511 ambient air to form a gaseous combustible mixture 512 surrounding the droplet. As a result, the ignition of the 513 droplet is found to be triggered by a region just off the droplet 514 surface. This phenomenon is attributed to the occurrence of 515 the Stefan flow of fuel vapor from the droplet surface that is 516 slow as a consequence of the increase in boiling temperature 517 and a decrease in diffusion coefficient. The current study also 518 shows that the entrapment of a more volatile component 519 within the heated droplet results in the fragmentation of the 520 droplet due to internal pressure build up. The following 521 concluding remarks can be drawn:
1. The temperature history of the droplet ignition shows 522 that the rate increase in temperature $\left(\frac{\mathrm{d} T}{\mathrm{~d} t}\right)$, which ${ }_{523}$ represents the evaporation rate of the droplet, increases 524 as the pressure of the vessel is increased. Since, for all 525 liquids, the coefficient of the thermal conductivity 526 increases with pressure, it suggests that the heat transfer 527 in the current work is dominated by conduction. 528

2. At constant pressure, the rate of evaporation of the 529 mixture's droplet increases with increasing RON. Since 530 the RON is a measure of auto-ignition or anti-knock 531 quality of the fuel, therefore, increasing the RON of the 532 fuel mixed with hexadecane has improved the auto- 533 ignition or anti-knock quality of the mixture. As a result, 534 although the evaporation rate of the mixture is increased, 535 the TI of the mixture increases exponentially as the fuel's 536 RON used in the mixture increases.

537

3. On the other hand, for a given fuel RON, the TI 538 decreases with increasing ambient pressure.

539

4. An empirical model is proposed, which shows the 540 dependency of the TI to the mixture's RON and vessel 541 pressure for the mixture ratio used in the current work. 542 It shows that, in the pressure range above 20 bar, the mix 543 with a $25 \%$ volume fraction of fuel having different RON 544 fuels does not delay the auto-ignition of the droplet. The 545 effect of fuel's RON to the droplet auto-ignition is 546 diminished at pressures above 20 bar. In other words, 547 the presence of the fuel in the lubricating oil surrogate 548 droplet does not affect the auto-ignition characteristics 549 of pure hexadecane droplets significantly at the pressure 550 range above 20 bar.

551

\section{FUTURE WORK}

552

The future studies are planned for a wider range of 553 hexadecane-fuel mixture's RON to be conducted at constant 554 and elevated pressures of the vessel, which includes the test 555 that will be carried out using the Rapid Compression Machine 556 (RCM) and Ignition Quality Tester (IQT).

\section{AUTHOR INFORMATION}

\section{Corresponding Author}

*E-mail: hmitsudharmadi@gmail.com.

\section{ORCID}

Hatsari Mitsudharmadi: 0000-0001-6575-1217 562

\section{Notes}

The authors declare no competing financial interest.

\section{ACKNOWLEDGMENTS}

565

The research reported in this publication was supported by the 566 Saudi ARAMCO in collaboration with the Clean Combustion 567 Research Center (CCRC) at King Abdullah University of 568 Science and Technology (KAUST) under the FUELCOM II 569 project. The authors express their appreciation to Mr. Adrian 570 Montiano for his help in setting up the experimental rig and 571 collecting the experimental data.

\section{NOMENCLATURE}

$\mathrm{CN}=$ cetane number

CVCC $=$ constant volume combustion chamber

$\mathrm{DCN}=$ derived cetane number

FACE-I = fuels for advanced combustion engines type I with 577 the octane number of 70 
579 IQT = Ignition Quality Tester

$580 \quad P=$ pressure inside the chamber [bar]

$581 P^{*}=$ pressure inside the chamber normalized by atmospheric pressure $\left(P^{*}=\frac{P}{P_{\text {atm }}}\right)$

582

583

584

585

586

587

588

589

590

591

592

593

594

595

596

597 (1) Amann, M.; Mehta, D.; Alger, T. Engine operating condition and 598 gasoline fuel composition effects on low-sp eed pre-ignition in high599 performance spark ignited gasoline engines. SAE Int. J. Engines 2011, $6004,274-285$.

601 (2) Zahdeh, A.; Rothenberger, P.; Nguyen, W.; Anbarasu, M.; 602 Schmuck-Soldan, S.; Schaefer, J.; Goebel, T. Fundamental Approach 603 to Investigate Pre-Ignition in Boosted SI Engines. SAE Int. J. Engines 604 2011, 4, 246-273.

605 (3) Zaccardi, J.-M.; Escudié, D. Overview of the main mechanisms 606 triggering low-speed pre-ignition in spark-ignition engines. Int. J. 607 Engine Res. 2014, 16, 152-165.

608 (4) Wang, Z.; Qi, Y.; He, X.; Wang, J.; Shuai, S.; Law, C. K. Analysis 609 of pre-ignition to super-knock:hotspot-induced deflagration to 610 detonation. Fuel 2015, 144, 222-227.

611 (5) Wang, Z.; Liu, H.; Song, T.; Qi, Y.; He, X.; Shuai, S.; Wang, J. 612 Relationship between super-knock and pre-ignition. Int. J. Engine Res. $6132015,16,166-180$.

614 (6) Sasaki, N.; Nakata, K. Effect of fuel components on engine abnormal 615 combustion. SAE Technical Paper 2012-01-1276, SAE Internationa, 6162012.

617 (7) Mansfield, A. B.; Chapman, E.; Briscoe, K. Effect of market 618 variations in gasoline composition on aspects of stochastic pre619 ignition. Fuel 2016, 184, 390-400.

620 (8) Kalghatgi, G. T.; Bradley, D. Pre-ignition and 'super-knock' in 621 turbo-charged spark-ignition engines. Int. J. Engine Res. 2012, 13, 622 399-414.

623 (9) Dahnz, C.; Spicher, U. Irregular combustion in supercharged 624 spark ignition engines-pre-ignition and other phenomena. Int. J. 625 Engine Res. 2010, 11, 485-498.

626 (10) Ohtomo, M.; Miyagawa, H.; Koike, M.; Yokoo, N.; Nakata, K. 627 Pre-ignition of gasoline-air mixture triggered by a lubricant oil droplet. 628 SAE Int. J. Fuels Lubr. 2014, 7, 673-682.

629 (11) Maharjan, S.; Qahtani, Y.; Roberts, W.; Elbaz, A. The effect of 630 pressure, temperature, and additives on droplet ignition of lubricant oil 631 and its surrogate. SAE Technical Paper 2018-01-1673, SAE Interna632 tional, 2018.

633 (12) Takeuchi, K.; Fujimoto, K.; Hirano, S.; Yamashita, M. 634 Investigation of engine oil effect on abnormal combustion in 635 turbocharged firect injection-spark ignition engines. SAE Int. J. Fuels 636 Lubr. 2012, 5, 1017-1024.

637 (13) Dahnz, C.; Han, K.-M.; Spicher, U.; Magar, M.; Schiessl, R.; 638 Maas, U. Investigations on pre-ignition in highly supercharged SI 639 engines. SAE Int. J. Engines 2010, 3, 214-224.

640 (14) Jatana, G. S.; Splitter, D. A.; Kaul, B.; Szybist, J. P. Fuel 641 property effects on low-speed pre-ignition. Fuel 2018, 230, 474-482.
(15) Kuboyama, T.; Moriyoshi, Y.; Morikawa, K. Visualization and 642 analysis of LSPI mechanism caused by oil droplet, particle and deposit 643 in highly boosted SI combustion in low speed range. SAE Int. J. 644 Engines 2015, 8, 529-537.

645

(16) Fei, S.; Wang, Z.; Qi, Y.; Wang, Y.; Zhang, H. Ignition of a 646 single lubricating oil droplet in combustible ambient gaseous mixture 647 under high-temperature and high-pressure conditions. Combust. Sci. 648 Technol. 2018, 2033-2052.

(17) Distaso, E.; Amirante, R.; Calò, G.; De Palma, P.; Tamburrano, 650 P.; Reitz, R. D. Investigation of lubricant oil influence on ignition of 651 gasoline -like fuels by a detailed reaction mechanism. Energy Procedia 652 2018, 148, 663.

(18) Kuti, O. A.; Yang, S. Y.; Hourani, N.; Naser, N.; Roberts, W. L.; 654 Chung, S. H.; Sarathy, S. M. A fundamental investigation into the 655 relationship between lubricant composition and fuel ignition quality. 656 Fuel 2015, 160, 605-613.

657

(19) Sakai, T.; Sadakata, M.; Saito, M. Single droplet combustion of 658 coal-methanol slurry. Fuel 1985, 64, 163-166.

659

(20) Kim, H.; Baek, S. W.; Chang, D. A single n-heptane droplet 660 behavior in rapid compression machine. Int. J. Heat Mass Transfer 661 2014, 69, 247-255.

662

(21) Kim, H.; Won, J.; Baek, S. W. Evaporation of a single emulsion 663 fuel droplet in elevated temperature and pressure conditions. Fuel 664 2018, 226, 172-180.

(22) Elbaz, A. M.; Khateeb, A. A.; Roberts, W. L. PM from the 666 combustion of heavy fuel oils. Energy 2018, 152, 455-465. 667 (23) Kim, H.; Baek, S. W.; Chang, D. Auto-ignition characteristics of 668 single n-heptane droplet in a rapid compression machine. Combust. 669 Sci. Technol. 2014, 186, 912-927.

670

(24) Law, C. K. Internal boiling and superheating in vaporizing 671 multicomponent droplets. AIChE J. 1978, 24, 626-632. 672

(25) Lugo, H. J.; Ragone, G.; Zambrano, J. Correlations between 673 octane numbers and catalytic cracking naphtha composition. Ind. Eng. 674 Chem. Res. 1999, 38, 2171-2176.

675

(26) Naser, N.; Yang, S. Y.; Kalghatgi, G.; Chung, S. H. Relating the 676 octane numbers of fuels to ignition delay times measured in an 677 ignition quality tester (IQT). Fuel 2017, 187, 117-127.

(27) Kubic, W. L. A Group Contribution Method for Estimating Cetane 679 and Octane Numbers (LA-UR-16-25529). Los Alamos National 680 Laboratory: New Mexico, USA, 2016.

(28) Albahri, T. A. Structural group contribution method for 682 predicting the octane number of pure hydrocarbon liquids. Ind. Eng. 683 Chem. Res. 2003, 42, 657-662.

(29) Kalghatgi, G. T. Auto-ignition quality of practical fuels and 685 implications for fuel requirements of future SI and HCCI engines. 686 SAE 2005 World Congress \& Exhibition, SAE International, 2005. 687 